\title{
Uremic Toxin Lanthionine Interferes with the Transsulfuration Pathway, Angiogenetic Signaling and Increases Intracellular Calcium
}

\author{
Carmela Vigorito ${ }^{1,2, \dagger}$, Evgeniya Anishchenko ${ }^{1,2, \dagger}$, Luigi Mele ${ }^{3}$, Giovanna Capolongo ${ }^{1}$, \\ Francesco Trepiccione ${ }^{1,4}$, Miriam Zacchia ${ }^{1}$, Patrizia Lombari ${ }^{1}$, Rosanna Capasso ${ }^{2}$, \\ Diego Ingrosso ${ }^{2,+}$ and Alessandra F. Perna ${ }^{1, *,+(\mathbb{C})}$ \\ 1 Department of Translational Medical Sciences, University of Campania “Luigi Vanvitelli," 80131 Naples, \\ Italy; ca.vigorito86@libero.it (C.V.); anishchenkoea@gmail.com (E.A.); giovi.capolongo@gmail.com (G.C.); \\ francesco.trepiccione@unicampania.it (F.T.); miriam.zacchia@unicampania.it (M.Z.); \\ patrizia.lombari@gmail.com (P.L.) \\ 2 Department of Precision Medicine, University of Campania “Luigi Vanvitelli,” 80138 Naples, Italy; \\ r.capasso74@icloud.com (R.C.); diego.ingrosso@unicampania.it (D.I.) \\ 3 Department of Experimental Medicine, University of Campania "Luigi Vanvitelli," 80138 Naples, Italy; \\ luigi.mele@unicampania.it \\ 4 Biogem A. C. S. R. L. Contrada Camporeale, 83031 Ariano Irpino AV, Italy \\ * Correspondence: alessandra.perna@unicampania.it; Tel.: +39-081-566-6822 \\ + These authors contributed equally to this work.
}

Received: 29 March 2019; Accepted: 6 May 2019; Published: 8 May 2019

\begin{abstract}
The beneficial effects of hydrogen sulfide $\left(\mathrm{H}_{2} \mathrm{~S}\right)$ on the cardiovascular and nervous system have recently been re-evaluated. It has been shown that lanthionine, a side product of $\mathrm{H}_{2} \mathrm{~S}$ biosynthesis, previously used as a marker for $\mathrm{H}_{2} \mathrm{~S}$ production, is dramatically increased in circulation in uremia, while $\mathrm{H}_{2} \mathrm{~S}$ release is impaired. Thus, lanthionine could be classified as a novel uremic toxin. Our research was aimed at defining the mechanism(s) for lanthionine toxicity. (2) The effect of lanthionine on $\mathrm{H}_{2} \mathrm{~S}$ release was tested by a novel lead acetate strip test (LAST) in EA.hy926 cell cultures. Effects of glutathione, as a redox agent, were assayed. Levels of sulfane sulfur were evaluated using the SSP4 probe and flow cytometry. Protein content and glutathionylation were analyzed by Western Blotting and immunoprecipitation, respectively. Gene expression and miRNA levels were assessed by qPCR. (3) We demonstrated that, in endothelial cells, lanthionine hampers $\mathrm{H}_{2} \mathrm{~S}$ release; reduces protein content and glutathionylation of transsulfuration enzyme cystathionine- $\beta$-synthase; modifies the expression of $\mathrm{miR}-200 \mathrm{c}$ and $\mathrm{miR}-423$; lowers expression of vascular endothelial growth factor VEGF; increases $\mathrm{Ca}^{2+}$ levels. (4) Lanthionine-induced alterations in cell cultures, which involve both sulfur amino acid metabolism and calcium homeostasis, are consistent with uremic dysfunctional characteristics and further support the uremic toxin role of this amino acid.
\end{abstract}

Keywords: lanthionine; glutathione; uremic toxin; chronic kidney disease; $\mathrm{H}_{2} \mathrm{~S}$; sulfane sulfur; CBS; CSE; VEGFA; calcium homeostasis

\section{Introduction}

Lanthionine is a non-protein amino acid generated as a side-product of trassulfuration, a two-step metabolic pathway catalyzed by cystathionine- $\beta$-synthase (CBS) and cystathionine- $\gamma$-lyase (CSE). Transsulfuration is a bifunctional pathway; in the complete classical mode, the two enzymes act in sequence, where CBS catalyzes the condensation of serine and homocysteine to form cystathionine; this in turn is hydrolyzed by CSE to $\alpha$-ketobutyrate and cysteine [1,2]. In the second more recently 
discovered way of action, transsulfuration enzymes may function independently from each other, catalyzing the formation of hydrogen sulfide $\left(\mathrm{H}_{2} \mathrm{~S}\right)$, the third gaseous vasodilator, mainly from two cysteine molecules and yielding lanthionine as a side product, with a one to one stoichiometric ratio to $\mathrm{H}_{2} \mathrm{~S}[3]$.

Lanthionine has been initially considered as a stable indicator of $\mathrm{H}_{2} \mathrm{~S}$ production in living systems [4,5]. It has been demonstrated that this amino acid accumulates in circulation in uremia and may inhibit transsulfuration enzymes in cell cultures, possibly contributing to the hyperhomocysteinemia almost constantly associated with uremia [6]. The uremic toxin characteristic of lanthionine has been further assessed in a zebrafish animal model, where it was demonstrated that lanthionine determines significant alterations of larval cardiovascular development, together with behavioral modifications; these alterations are partly reversible upon glutathione treatment [7].

It has been established that $\mathrm{H}_{2} \mathrm{~S}$ is present in various forms. The free gaseous form is volatile and difficult to detect, nevertheless the product of $\mathrm{H}_{2} \mathrm{~S}$ interactions with other species yields sulfane sulfur, which include persulfides (R-S-SH), polysulfides (R-S $\mathrm{S}_{\mathrm{n}} \mathrm{SH}$ or R-S-S $\mathrm{S}_{\mathrm{n}} \mathrm{S}-\mathrm{R}$ ), inorganic hydrogen polysulfides $\left(\mathrm{H}_{2} \mathrm{~S}_{n}, n \geq 2\right)$ and protein-bound elemental sulfur $\left(\mathrm{S}^{8}\right)$. Sulfane sulfur related species are generated following the oxidation of cellular $\mathrm{H}_{2} \mathrm{~S}$ and they are thought to serve as a source of endogenously released $\mathrm{H}_{2} \mathrm{~S}$ [8-10]. Bound sulfane sulfur, rather than free $\mathrm{H}_{2} \mathrm{~S}$, appeared to be altered in uremia [6]. Detection of both gaseous $\mathrm{H}_{2} \mathrm{~S}$ and sulfane sulfur is indeed a way to gain information on the effects of lanthionine and its mechanism(s) of action as an uremic toxin, as well as on the general availability of $\mathrm{H}_{2} \mathrm{~S}$ in cell cultures [11].

We therefore studied the effects of lanthionine in a human endothelial cell line i) on $\mathrm{H}_{2} \mathrm{~S}$ release and sulfane sulfur cellular content; ii) CBS protein content and glutathionylation; iii) the expression of relevant miRNA; iv) the expression of VEGFA and v) intracellular $\mathrm{Ca}^{2+}$ levels.

\section{Results}

\subsection{Lanthionine Decreases $\mathrm{H}_{2} \mathrm{~S}$ Release and Sulfane Sulfur Cell Content as well as CBS Protein Levels}

In order to measure the effects of lanthionine on the release of $\mathrm{H}_{2} \mathrm{~S}$, as well as on sulfane sulfur content, endothelial EA.hy926 cells were treated with lanthionine, at concentrations comparable with those detected in vivo in uremia [6]. Treatments were also applied under condition maximizing the stimulation of the activity of transsulfuration enzymes, i.e., in the presence of vitamin $\mathrm{B}_{6}$, the precursor of pyridoxal phosphate, needed as a coenzyme of both CBS and CSE; cysteine, the substrate for $\mathrm{H}_{2} \mathrm{~S}$ biosynthesis; $S$-adenosylmethionine, an allosteric powerful CBS activator.

Stimulated cell conditions were highly effective to trigger $\mathrm{H}_{2} \mathrm{~S}$ release, particularly after the $12 \mathrm{~h}$ treatment (Figure 1a). Treatment with lanthionine during $12 \mathrm{~h}$ and $24 \mathrm{~h}$ both caused a $43 \%$ reduction of $\mathrm{H}_{2} \mathrm{~S}$ release respect to the stimulated controls (Figure 1a,b). Conversely, glutathione (GSH) treatment induces a $80 \%$ and $27 \%$ increase of $\mathrm{H}_{2} \mathrm{~S}$ release, with respect to the stimulated controls during $12 \mathrm{~h}$ and $24 \mathrm{~h}$ of treatment, respectively (Figure 1a,b). Lanthionine, in the absence of GSH, exerted a significant long-lasting effect on $\mathrm{H}_{2} \mathrm{~S}$ release (Figure 1a,b). After $24 \mathrm{~h}$ incubation, the recovery upon lanthionine and GSH combined treatment was prevalent on inhibition of $\mathrm{H}_{2} \mathrm{~S}$ release induced by lanthionine alone (Figure 1b). It appears however that the kinetics of the recovery of gaseous $\mathrm{H}_{2} \mathrm{~S}$ release and sulfane sulfur increase are quite different upon the addition of both GSH and lanthionine, or GSH alone in the medium, compared to lanthionine treatment. This may reflect the different metabolism of these two sulfur-containing species.

Enzyme protein content was analyzed by Western blotting (Figure 1c,d and Figure S1). It appears that in the samples treated with lanthionine at $12 \mathrm{~h}$ CBS is reduced, while CSE is almost unchanged (Figure 1c and Figure S1a,c). In addition, the difference in the intensities of CBS bands in Figure 1c,d is consistent with the apparent difference in the stimulated vs. non-stimulated levels of $\mathrm{H}_{2} \mathrm{~S}$ release in Figure $1 \mathrm{a}, \mathrm{b}$ respectively. This suggests that the stimulation cocktail has a much stronger stabilizing effect on the CBS protein during the shorter incubation range. 


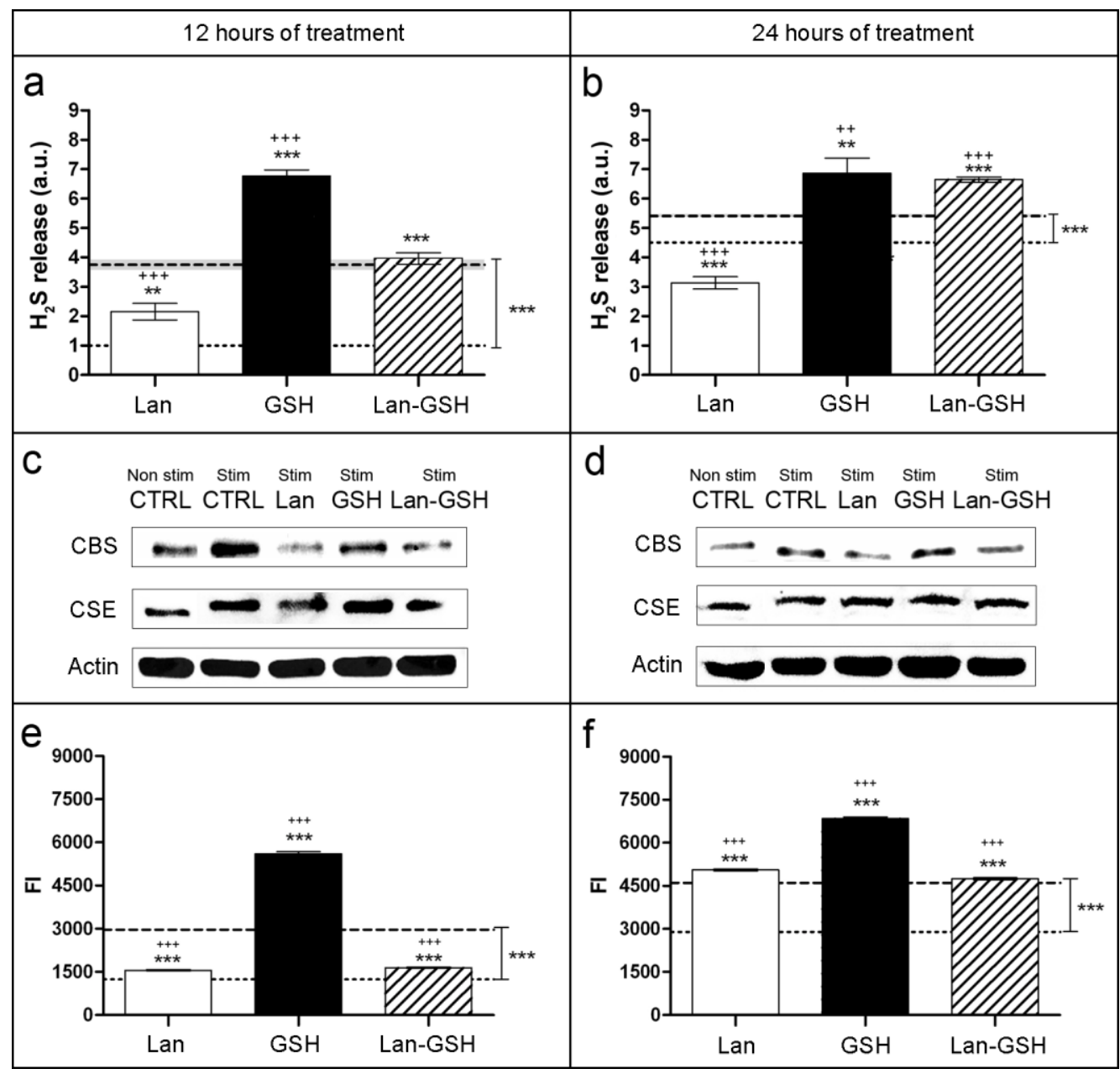

Figure 1. Effects of lanthionine on $\mathrm{H}_{2} \mathrm{~S}$ release, sulfane sulfur levels, CBS and CSE protein levels. Cells were incubated with $0.3 \mu \mathrm{M}$ lanthionine and/or $1 \mathrm{mM} \mathrm{GSH}$, under "stimulated" conditions. $\mathrm{H}_{2} \mathrm{~S}$ release in $12 \mathrm{~h} \mathrm{(a)} \mathrm{and} \mathrm{in} 24 \mathrm{~h}$ (b) is expressed in arbitrary units (a.u.) normalized to the untreated (non-stimulated) control at $12 \mathrm{~h}$, which is made equal to 1 . Western blot analysis of CBS and CSE proteins abundance in samples treated during $12 \mathrm{~h} \mathrm{(c)} \mathrm{and} 24 \mathrm{~h}(\mathrm{~d})$ is shown; $\beta$-actin is the loading control. Relative quantity of sulfane sulfur species in endothelial cells, treated for $12 \mathrm{~h}(\mathbf{e})$ and in $24 \mathrm{~h}$ (f), were detected using fluorescent probe SSP4 and expressed as fluorescence intensity (FI). In a,b,e,f, dotted lines indicate the average values of untreated controls and bold dashed lines indicate the average values of stimulated control. In all experiments Lan, GSH, Lan with GSH and stimulated controls were incubated with $1 \mathrm{mM}$ Cys, $1 \mathrm{mM}$ vitamin $\mathrm{B}_{6}$ and $5 \mu \mathrm{M} \mathrm{SAM}, 2 \mathrm{~h}$ before treatment started. In a and $\mathrm{b}$ the columns represent the mean and error bars indicating the SD from three independent experiments. Gray area behind bold dashed lines represent the SD for stimulated controls; $p$ value versus untreated control $={ }^{* *} p<0.01,{ }^{* * *} p<0.001$, while $p$ value versus stimulated control $={ }^{++} p<0.01,{ }^{+++} p<0.001$ (according to Student's $t$-test). In e and $\mathrm{f}$, the columns represent the mean and error bars indicate the percent coefficient of variation (\%CV) of $10^{4}$ events; $p$ value versus untreated control $={ }^{* * *} p<0.001$, while $p$ value versus stimulated control $={ }^{+++} p<0.001$ (according to Student's $t$-test). CTRL, control; Lan, lanthionine; GSH, glutathione; CBS, cystathionine- $\beta$-synthase; CSE, cystathionine- $\gamma$-lyase; Cys, cysteine; SAM, S-adenosyl-L-methionine.

In the same cell model, the effect of lanthionine on sulfane sulfur content was evaluated. An inhibitory effect of lanthionine on sulfane sulfur content could only be detected at $12 \mathrm{~h}$ incubation with respect to the stimulated sample signal (Figure 1e), while after $24 \mathrm{~h}$ incubation, such inhibitory effect of lanthionine on sulfane sulfur levels could no longer be detected (Figure 1f). As expected [10,12], GSH appears to significantly increase sulfane sulfur under stimulated conditions (Figure 1e,f). Combined 
treatments with lanthionine plus GSH resulted in the almost total abolishment of lanthionine effect on $\mathrm{H}_{2} \mathrm{~S}$ release, with respect to GSH alone, at $24 \mathrm{~h}$ (Figure $1 \mathrm{~b}$ ). On the other hand, a long lasting effect of lanthionine on sulfane sulfur levels is residual at $24 \mathrm{~h}$, compared with the samples where GSH alone is present (compare Figure $1 \mathrm{~b}, \mathrm{f}$ ). This may support the interpretation that higher concentrations of glutathione persulfide (GSSH) may indeed be present in the samples incubated with GSH plus lanthionine, and $\mathrm{H}_{2} \mathrm{~S}$ can actually be more easily generated from persulfide degradation in the samples where lanthionine is also present. This is consistent with the notion that sulfane sulfur is lower in high lanthionine uremic serum samples, compared to normal [6].

\subsection{Lanthionine Hampers CBS Glutathionylation}

It has been shown that post-biosynthetic enzymatic glutathionylation of $\mathrm{Cys}_{346}$ of CBS significantly increases its activity [13]. In order to check the extent of CBS glutathionylation under our experimental conditions, we processed cell extracts treated with lanthionine and/or GSH. Proteins were immunoprecipitated with a monoclonal anti-GSH antibody and separated by Western blotting, where detection antibody was a monoclonal anti-CBS.

Results in Figure 2 and Figure S2 show that lanthionine decreased CBS glutathionylation by about $20 \%$, according to ImageJ analysis. During longer exposure, as shown in Figure 2a, row II, the increased detection sensitivity could reveal, according to ImageJ analysis, $60 \%$ decreased glutathionylation caused by lanthionine supplement (inset in Figure S2). GSH, as expected, increased glutathionylation approximately eight folds with respect to the control. Again, the addition of lanthionine to GSH lowered glutathionylation by about $20 \%$.

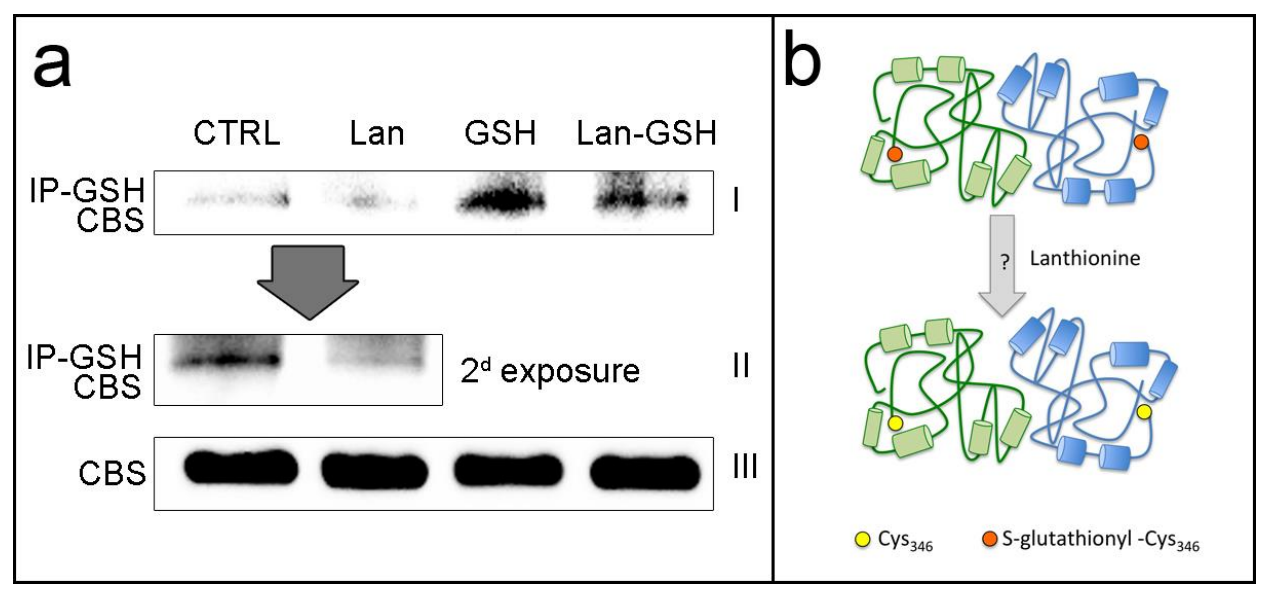

Figure 2. Effect of lanthionine on CBS glutathionylation. (a) Endothelial cells were treated with $0.3 \mu \mathrm{M}$ lanthionine and/or with $1 \mathrm{mM}$ GSH during $24 \mathrm{~h}$. These experiments were accomplished without pre-incubation with the stimulation cocktail, because under stimulating conditions lanthionine significantly reduces the amount of CBS protein, which may interfere with the evaluation of the amount of immunoprecipitated protein. Western blotting shows the analysis of cell protein extracts. First two rows from top (I and II), proteins were immunoprecipitated with anti-GSH antibodies (IP-GSH) and subsequently detected with anti-CBS antibody. Row II: 2nd (prolonged) exposure of the half left part of row I, more clearly showing the difference between lanthionine treated cells and control samples. Row III (CBS); non immunoprecipitated parallel samples treated as in I and II, showing that the initial amounts of CBS was the same in all starting extracts. (b) Tentative scheme depicting summarily the possible interpretation of our findings presented in a. According to this model lanthionine lowers CBS activity by hampering CBS activation induced by GSH-dependent glutathionylation. The actual mechanism is not known. Cys, cysteine; CTRL, control; Lan, lanthionine; GSH, glutathione.

We interpreted this result as the ability of lanthionine of directly interfering with CBS glutathionylation, possibly by hampering GSH availability at $\mathrm{Cys}_{346}$ site. This mechanism can 
be expected to sum up with respect to lanthionine's ability to downregulate CBS expression as seen in Figure 1c,d.

\subsection{Lanthionine is Involved in Fundamental Angiogenic Pathways}

Previous results have shown that lanthionine induces significant changes in the miRNA pattern in zebrafish larvae; these changes were partly comparable to some miRNA modifications detected in uremia [7]. In this work, we undertook a literature search and choose miR-200c and miR-423 since they are altered in kidney disease [14-20]. Here, we demonstrated that in EAhy926 the expression of miR-200c and miR-423 was affected by lanthionine treatment compared to the untreated control (Figure 3).

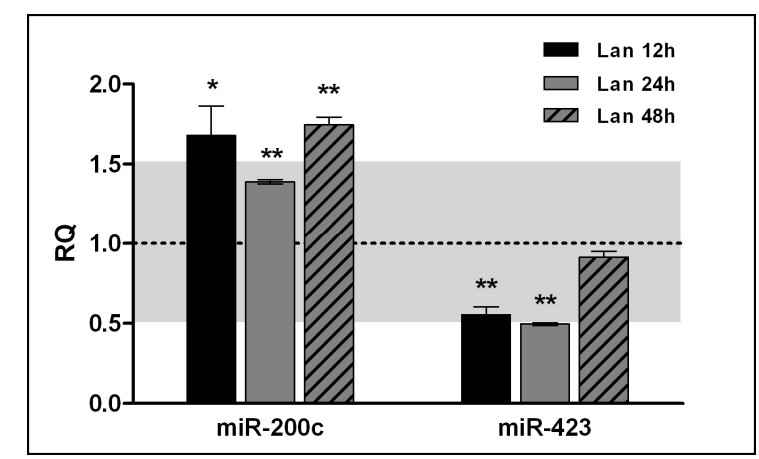

Figure 3. Effect of lanthionine on microRNAs in endothelial cells. Fold changes in miR-200c and miR-423 levels after $12 \mathrm{~h}, 24 \mathrm{~h}$ and $48 \mathrm{~h}$ of treatment with $0.3 \mu \mathrm{M}$ lanthionine in endothelial cells. Untreated control; dashed baseline. The gray area behind the dashed baseline, corresponding, on the $y$ axis, to RQ $0.5-1.5$, indicates an area of variations of microRNA levels which may be considered physiological with respect to the control. The columns represent the mean and error bars indicating the SD from three independent experiments; $p$ values versus untreated control ${ }^{*} p<0.05,{ }^{* *} p<0.01$ (according to Student's $t$-test).

In consideration of the implications of uremic toxins in the increased cardiovascular risk, we focused on potential targets of miR-200c and/or miR-423, which may be indeed involved in the pathophysiology of vascular endothelial damage. Our in silico bioinformatics prediction based on the KEGG pathway collection database showed that both miR-200c and miR-423 may exert potential regulatory role in the expression of VEGFA (Table S1). While the role of miR-423 on VEGFA regulation is still uncertain, miR-200c has been described to actually downregulate VEGFA expression in cell cultures [21].

Lanthionine treatment was effective to reduce VEGFA protein levels in a time-dependent fashion (Figure 4a,b). Real-time PCR was used in order to accomplish an extended quantitative analysis of VEGFA transcript levels in endothelial EA.hy926 treated with lanthionine. Results in Figure 4c show that all isoforms could be detected, although isoform 145 was affected by the highest experimental detection variability, likely due to its low expression levels, as described by others [22]. In addition, results indicated that the $12 \mathrm{~h}$ treatment with lanthionine determines a general downregulation of VEGFA expression, except in the case of isoform 165 (Figure 4c). Lanthionine treatment at $12 \mathrm{~h}$ is consistent with decreased mRNA and protein levels as seen in Figure $4 \mathrm{a}-\mathrm{c}$. While longer treatments ( $24 \mathrm{~h}$ and $48 \mathrm{~h}$ ) showed the lesser inhibitory effect on protein levels, those may be explained by the rebound in transcript levels detected for several isoforms (Figure 4). The system seems to reach a stabilization after $48 \mathrm{~h}$ of treatment with lanthionine. 


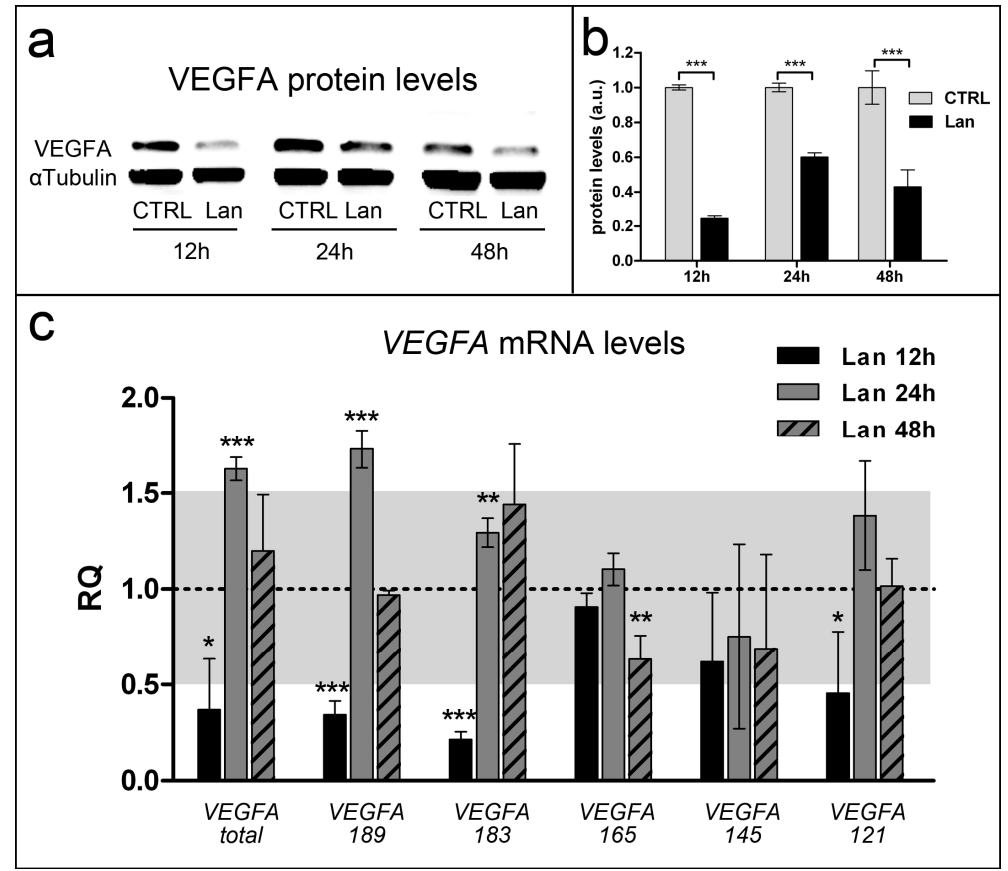

Figure 4. Molecular characterization of intracellular VEGFA levels in endothelial cells after $0.3 \mu \mathrm{M}$ lanthionine treatment in $12 \mathrm{~h}, 24 \mathrm{~h}$ and $48 \mathrm{~h}$. (a) Western blot analysis of VEGFA protein abundance in endothelial cells; $\alpha$ Tubulin is the loading control; (b) relative differences in protein levels shown in (a) were quantitated by using Image software, normalized to $\alpha$ Tubulin levels and expressed as arbitrary units (a.u.). (c) Relative quantitation (RQ) of the expression levels of VEGFA isoform transcripts (total VEGFA includes all isoforms, VEGFA-121, -145, -165, -183, -189), using qPCR method, in comparison to the untreated control shown as a dashed baseline and made equal to 1. Alterations of mRNA levels, which are being considered physiological with respect to the control, fall within the gray area between 0.5 and 1.5 RQ. The columns in $\mathbf{b}$ and $\mathbf{c}$ represent the mean and error bars indicate the SD from three independent experiments; $p$ value versus untreated control $={ }^{*} p<0.05,{ }^{* *} p<0.01 ;{ }^{* *} p<0.001$, (according to Student's $t$-test). CTRL, control; Lan, lanthionine; VEGFA, vascular endothelial growth factor A.

\subsection{Lanthionine Increases Intracellular Calcium Levels}

Intracellular calcium levels are important determinants of vascular homeostasis and are connected with both $\mathrm{H}_{2} \mathrm{~S}$ and VEGFA functions [23]. We then monitored calcium levels in our system by using a fluorescent specific probe. Lanthionine treatment induced a rise of intracellular calcium ion concentrations, which decayed with time to reach the level of control within $48 \mathrm{~h}$ of treatment (Figure 5). 


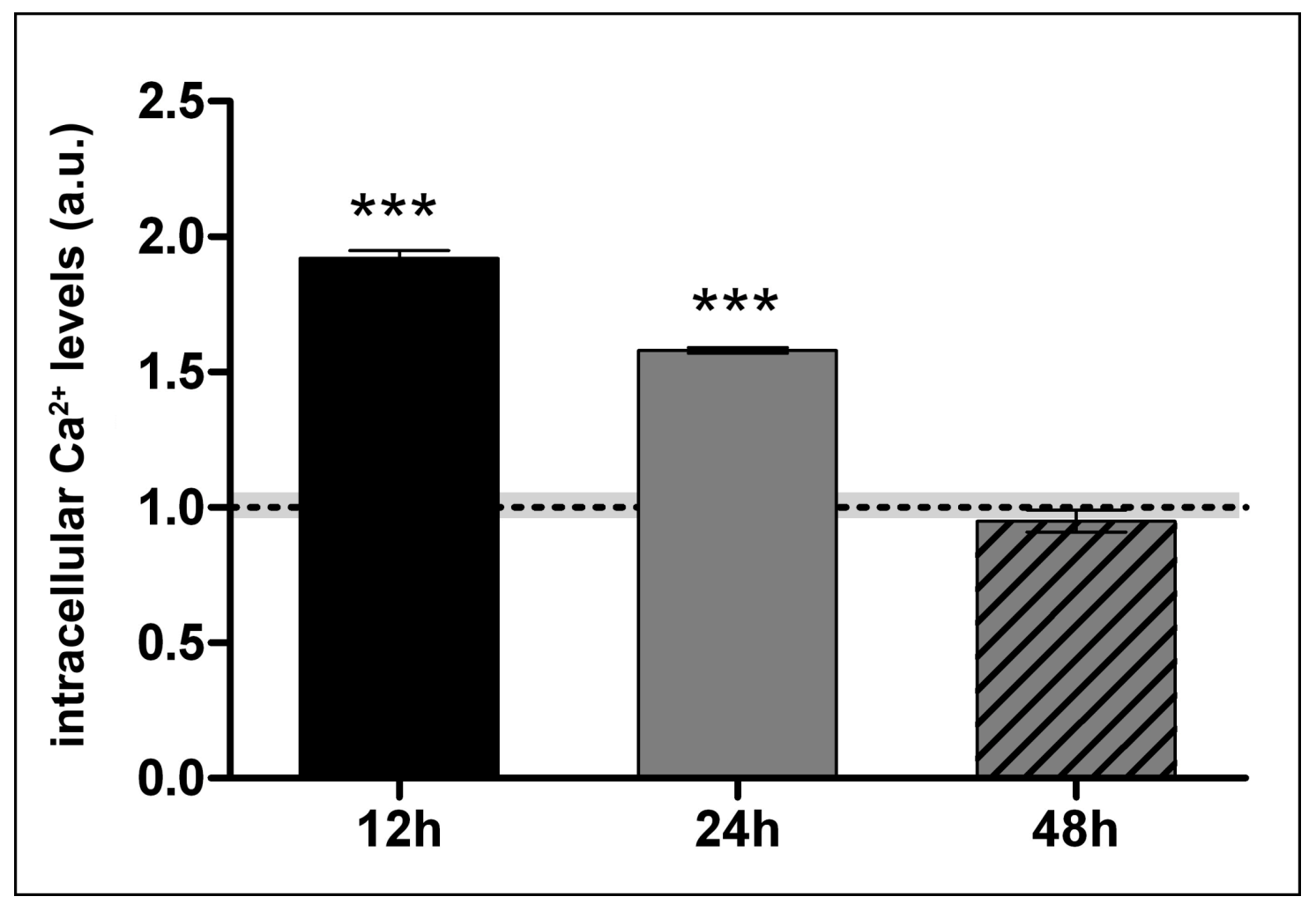

Figure 5. Effect of $0.3 \mu \mathrm{M}$ lanthionine treatment in $12 \mathrm{~h}, 24 \mathrm{~h}$ and $48 \mathrm{~h}$ on intracellular $\mathrm{Ca}^{2+}$ levels in endothelial cells. $\mathrm{Ca}^{2+}$ levels were detected using the fluorescent probe Fura 2-AM and were expressed as arbitrary units (a.u.), normalized to fluorescence intensity in lanthionine free control cells (dashed line). The columns represent the mean and error bars indicating the SD from three independent experiments; gray area represents the SD for control samples; $p$ value versus untreated control $={ }^{* * *} p<0.001$, (according to Student's $t$-test). CTRL, control; Lan, lanthionine; $\mathrm{Ca}^{2+}$, calcium.

\section{Discussion}

The data presented here deal with three aspects of lanthionine activity as an uremic toxin: (a) the possibility that a reducing microenvironment could relieve lanthionine's deleterious effects; (b) the way of action of lanthionine on transsulfuration enzymes; (c) the mechanism(s) through which lanthionine may exert its cardiovascular toxicity by interfering with pathways connected to vascular homeostasis.

Lanthionine is a naturally occurring amino acid, produced during the enzymatic biosynthesis of $\mathrm{H}_{2} \mathrm{~S}$ from condensation of two cysteine molecules. In vivo, $\mathrm{H}_{2} \mathrm{~S}$ is normally produced in many tissues and also the microbiota contributes to its production [24]. One major issue is the way trassulfuration enzymes are regulated in order to partition their activity between $\mathrm{H}_{2} \mathrm{~S}$ biosynthesis and the classical trassulfuration, leading to the formation of cysteine from homocysteine. In uremia there is a profound dysregulation of sulfur amino acid metabolism, in that homocysteine is often increased in circulation and also a number of other sulfur-containing intermediates are altered, including $S$-adenosylhomocysteine $[25,26]$. Lanthionine has been found to accumulate by almost two orders of magnitude in uremic serum. This increase has been related to some important consequences: first, its possible interference with metabolic pathways; second, its possible ability to disrupt tissue and organ function in renal disease. A striking example of the first was the evidence that lanthionine could hamper $\mathrm{H}_{2} \mathrm{~S}$ release in cell cultures [6]. Taking into account that transsulfuration enzymes are devoted to both homocysteine metabolism and $\mathrm{H}_{2} \mathrm{~S}$ biosynthesis, it should be expected that any inhibitory mechanism could affect both functions. The effect of lanthionine may contribute to an overall impairment of transsulfuration, thus help explaining the presence of a very high prevalence of hyperhomocysteinemia in uremia, which so far has otherwise gone unexplained. As far as the second 
aspect is concerned, previous evidence showed that such damaging effects do actually take place in zebrafish, although the molecular mechanism was still elusive [7]. Data presented here showed that the induction of a more reducing cellular microenvironment, due to the presence of GSH, tends to hamper lanthionine effects on the transsulfuration enzyme CBS. Moreover, evidence supports a model of action of lanthionine, according to which this amino acid may interfere with the ability of GSH to activate CBS by forming a complex with this enzyme. We found that lanthionine, under stimulating cell conditions, determined a significant reduction of CBS cell content. On the other hand, from the results reported in Figure 2, we could rule out that the decrease of glutathionylation may affect CBS stability in lanthionine-treated cells, because no appreciable changes in CBS levels before immunoprecipitation, could be detected in cells treated with lanthionine compared to control, as well as in the other lanes (Figure 2a row III). On the other hand, we had designed the immunoprecipitation experiment in order to prevent any CBS variations to actually occur and also to avoid confounding due to a CBS protein decrease. Of course, we cannot rule out that in vivo, under stimulating conditions, CBS decrease and reduced glutathionylation may exert a synergic negative effect on the activity of this enzyme.

Our results also showed altered expression levels of miR-200c and miR-423. It has been reported that the same miRNAs are also altered in kidney disease [14]. In addition, target prediction analysis revealed the existence of over 1000 mRNA targets of miR-200c and miR-423, regulating pathways perturbed in various kidney pathologies [14]. These two miRNAs were described as a sensitive (and noninvasive) indicators of kidney damage [15]. The upregulation of miR-200c in inner kidney medulla was observed in $24 \mathrm{~h}$ dehydrated mice [16]. Patients with minimal change nephropathy or focal glomerulosclerosis had higher urinary miR-200c levels than those with non-renal diagnoses [17]. miR-200c showed altered expression in various kidney diseases [18]. Renal cortical content of miR-200c was increased with aging [19]. Alb/TGF $\beta$ mice overexpress TGF- $\beta$ and spontaneously develop renal fibrosis and chronic kidney disease (CKD) with age. qRT-PCR studies showed that miR-423-5p was 2.8-fold downregulated in the plasma of Alb/TGF $\beta$ mice, confirming the observation from the human studies where levels of miR-423-5p was 2.2-fold downregulated in plasma of patients with estimated glomerular filtration rate (eGFR) $<30 \mathrm{~mL} / \mathrm{min}[20]$.

Our prediction analysis showed that VEGFA is a target of both miR-200c and miR-423. Trying to understand the potential contribution of lanthionine-induced VEGFA impairment, according to our present data, it should be pointed out that VEGFA is also a potent mitogen for micro- and macro-vascular endothelial cells derived from arteries, veins, and lymphatic vessels [27]. It has been reported that VEGFA inhibition or reduction could result in thrombotic microangiopathy with renal involvement $[28,29]$. Reduction of VEGFA production by the podocytes may lead to loss of glomerular cells with consequent mesangiolysis. VEGF is required for the proliferation, differentiation, and survival of mesangial and endothelial cells [30].

VEGFA gene encodes for various protein products, with differential cell distribution, solubility or membrane bound characteristics. Based on their amino acids length, the following six isoforms, generated through alternative splicing of the primary transcript, have been described: VEGFA-121, VEGFA-145, VEGFA-165, VEGFA-183, VEGF-189, and VEGFA-206 [31]. VEGFA gene contains eight exons, which are assembled in the final products, so that exons 1 to 5 plus 8 are common to all isoforms. Exon 8 in particular is necessary for the stimulation of mitosis. Then, exon 6 is absent in VEGFA-121 and VEGFA-165; exon 7, which is absent in the isoform 121, contains the heparin-binding site, thus becoming soluble [27,32-34]. VEGFA-183 and VEGF-189 are both membrane-bound and differ for only 6 amino acid residues; their functional peculiarities are still partly undetermined [35]. VEGFA-121 and VEGFA-165 are generally the most abundant variants expressed by the examined tissues, followed by VEGFA-189 and VEGFA-183, while VEGFA-145 is detected in small amounts. The expression profile of VEGF splice variants displayed significant heterogeneity between the examined tissues and cell lines [22]. Studies on the structure-function relationships in VEGFA isoforms introduced the concept that they are characterized by different degrees of disorder and flexibility [36]. 
We found that lanthionine, although generally reducing VEGFA expression, does not affect all isoform expression to the same extent. The affinity for heparin may profoundly affect the bioavailability of VEGF. All VEGFA isoforms, apart from VEGF-121, bind to heparan sulfate or to heparin. VEGF-121 fails to bind to heparin and, therefore, is a freely soluble protein; we found that the expression of this isoform strongly reduced. In contrast, VEGF-189, whose expression is strongly affected by lanthionine, binds to heparin with high affinity and consequently, this isoform is almost completely sequestered in the extracellular matrix. It has been shown that heparin augments the interaction of VEGF-165 with VEGFR2 [37]. VEGF-165 has intermediate properties, as it is secreted and then circulates as a diffusible protein, but a significant fraction remains bound to the cell surface and the extracellular matrix. VEGFA-165 production is not significantly affected by lanthionine treatment. However, the isoforms bound to the extracellular matrix may be released in a diffusible form by heparin, heparinase, or plasmin. Therefore, VEGF-165 may act both as a diffusible factor and as a heparin binding form that is released upon heparin induced cleavage [27]. Heparin may represent indeed an important variable in the uremic microenvironment, influencing VEGF bioavailability in circulation.

One important lanthionine effect is its influence on calcium levels detected in our model system. The mechanism through which lanthionine induces intracellular $\mathrm{Ca}^{2+}$ increase is not known. It should be underscored, in this respect, that calcium deposition in the vasculature is a major mechanism contributing to the generation of vascular damage and cardiovascular risk increase in uremia [38]. As far as lanthionine uremic toxicity mechanism is concerned, we found that lanthionine treatment induces an increase of intracellular calcium, while reducing $\mathrm{H}_{2} \mathrm{~S}$ release and endogenous sulfane sulfur content. Under these conditions VEGFA expression was reduced, particularly under initial treatment conditions. These results point to a paradoxical behavior, induced by lanthionine in this model, because previous studies showed that VEGF in the short time range stimulates calcium signaling, which was mediated by $\mathrm{H}_{2} \mathrm{~S}$, since this response was inhibited by propargylglycine, a well-known inhibitor of the transsulfuration enzyme CSE [23]. Our results suggest the hypothesis that lanthionine may interfere with the coupling of calcium signaling and VEGF and that this may no longer be tied correctly to $\mathrm{H}_{2} \mathrm{~S}$. The idea that lanthionine may dissociate calcium response to VEGF is also supported by the evidence that VEGF per se is an activator of calcium signaling in brain microvascular cell systems as well as in aortic rings [39]. It should be pointed out, in this respect, that nitric oxide (NO) plays an important role in this interaction. In fact, VEGF activates both eNOS and CSE, thus triggering production of both $\mathrm{NO}$ and $\mathrm{H}_{2} \mathrm{~S}$. The two gases, in turn, act synergistically, by activating soluble guanylyl cyclase (NO) and inhibiting phosphodiesterase $\left(\mathrm{H}_{2} \mathrm{~S}\right)$, respectively [39]. On the other hand, it has been shown that NO plays an inhibitory effects on $\mathrm{H}_{2} \mathrm{~S}$ production by CBS [40,41]. At present, we do not have direct information of eNOS activity and NO release in our experimental conditions. However, this aspect may certainly deserve attention in future investigations.

\section{Materials and Methods}

\subsection{Cell Culture and Treatments}

Human EA.hy926 cell line (ATCC) was grown in DMEM medium with 10\% Fetal Bovine Serum (S1810-500, Microtech, Pozzuoli, NA, Italy), 2 mM L-glutamine (X0550-100, Microtech, Pozzuoli, NA, Italy) and $0.1 \%$ penicillin-streptomycin (L0022-100, Microtech, Pozzuoli, NA, Italy). Cells were grown at $37^{\circ} \mathrm{C}$ in a humidified atmosphere with $5 \% \mathrm{CO}_{2}$.

For $\mathrm{H}_{2} \mathrm{~S}$ release detection experiments, cells were plated in cell culture flasks $14 \mathrm{~h}$ before any experiment. Experiment was performed in flasks, each containing 600,000 cells. Cells treatments under stimulating conditions (referred to as "stimulated") were performed by supplying cells in the presence of final concentrations of the following compounds: 1mM DL-cysteine (Cys, 861677, Aldrich, St.Louis, MO, USA), $1 \mathrm{mM}$ pyridoxine hydrochloride (B6, P6280, Sigma, St.Louis, MO, USA) and $5 \mu \mathrm{M}$ S-adenosyl-L-methionine (SAM, B9003S, New England Biolabs Inc, Ipswich, MA, USA). Cys-B6-SAM "stimulated" pre-treatment was initiated $2 \mathrm{~h}$ before the main treatment procedure. The latter consisted 
of cell treatment with $1 \mathrm{mM}$ reduced L-glutathione (GSH, G6013, Sigma, St.Louis, MO, USA) and/or $0.3 \mu \mathrm{M}$ DL-lanthionine (Lan, L0010, TCI, Tokyo, Japan). The concentration of lanthionine was based on the actual concentration detected in uremic serum [6]. DL-lanthionine solubility is $50 \mathrm{mg} / \mathrm{mL}$ in 1 $\mathrm{M} \mathrm{HCl}(240 \mathrm{mM})$. A $10^{5}$ fold dilution of the lanthionine stock in DMEM was prepared. The effect of solvent, in terms of $\mathrm{HCl}$ addition to DMEM could be indeed considered negligible, also by considering that neither $\mathrm{pH}$ variation nor effect on cell vitality could be detected.

To study VEGFA and miRNA expression, cells were treated with $0.3 \mu \mathrm{M}$ lanthionine during 12,24 and $48 \mathrm{~h}$. Cells were grown in six well plates, 200,000 cells per well.

For intracellular calcium levels measurements, cells were treated with $0.3 \mu \mathrm{M}$ lanthionine during $12 \mathrm{~h}, 24 \mathrm{~h}$ and $48 \mathrm{~h}$. Cells were grown in 24 well plates, 30,000 cells per well.

\section{2. $\mathrm{H}_{2} \mathrm{~S}$ Detection and Quantitation}

$\mathrm{H}_{2} \mathrm{~S}$ detection was performed using the method LAST [11]. This method, based on lead acetate test strips (06728, Sigma-Aldrich, St.Louis, MO, USA), detects $\mathrm{H}_{2} \mathrm{~S}$ on contact with lead acetate forming a black precipitate, indicated by a visible black-colored reaction on the paper strip. In brief, $\varnothing 4 \mathrm{~mm}$ sterile lead-containing paper strips were attached to the inner side of the lids of cell culture flasks, in order to become directly exposed to $\mathrm{H}_{2} \mathrm{~S}$ release during treatments. At the end of incubation (12 $\mathrm{h}$ and $24 \mathrm{~h}$ of exposure) lead-containing paper strips were scanned and analyzed using imageJ software (National Institutes of Health, Bethesda, MD, USA) to quantitate the intensity of black-stained precipitates. The amount of released $\mathrm{H}_{2} \mathrm{~S}$ was normalized in arbitrary units in comparison to untreated control (CTRL) after $12 \mathrm{~h}$ of treatment. Samples were always analyzed in triplicate. Results represent the mean and SD of three independent biological repeats.

\subsection{Sulfane Sulfurs Detection}

Sulfane sulfurs detection in EA.hy926 cells was performed using a fluorescent Sulfane Sulfur Probe 4 (SSP4; SB10, Dojindo Laboratories, Kumamoto, Japan). Reactions were performed as previously described [11]; in brief, cells were incubated with $1.5 \mu \mathrm{M} \mathrm{SSP4}$ probe in serum free Dulbecco's Modified Eagle's Medium without Phenol Red (DMEM; D4947, Sigma, St.Louis, MO, USA) with $150 \mu \mathrm{M}$ cetyl-trimethylammonium bromide (CTAB; H9151, Sigma, St.Louis, MO, USA) for 15 min at $37^{\circ} \mathrm{C}$ in a humidified atmosphere with $5 \% \mathrm{CO}_{2}$, afterwards cells were washed twice with PBS. Fluorescence was measured using flow cytometry (Accuri ${ }^{\mathrm{TM}}$ C6 Plus, BD Biosciences, San Jose, CA, USA), in the green channel (FITC). Experiments were performed in triplicate and data were analyzed using the GraphPad Prism software.

\subsection{Measurement of the Intracellular $\mathrm{Ca}^{2+}$ Concentration Ratio}

Measurement of $\mathrm{Ca}^{2+}$ in EA.hy926 cells was performed using a fluorescent Fura 2-AM probe (F1201, ThermoFisher Scientific, Milan, Italy). Reactions were performed according to the supplier's protocol. Briefly, cells were washed twice in PBS and incubated with $3 \mu \mathrm{M}$ probe in PBS for $30 \mathrm{~min}$ at $37^{\circ} \mathrm{C}$ in a humidified atmosphere with $5 \% \mathrm{CO}_{2}$. At the end of incubation cells were washed with PBS. Then, the fluorescence intensity was detected at $\lambda_{\mathrm{Ex}} 340 \mathrm{~nm}$ and $\lambda_{\mathrm{Em}} 510 \mathrm{~nm}$ by a fluorescence multi-reader (Infinite 200, Tecan Trading AG, Männedorf, Switzerland). Experiments were performed in triplicate and the data were analyzed using GraphPad Prism software.

\subsection{Protein Extraction}

Proteins were extracted using RIPA buffer (TCL131, HiMedia, Mumbai, India) containing a cocktail of protease inhibitors (11836153001, Roche, Milan, Italy). Protein concentrations were determined according to Bradford (Bradford Protein Assay Kit; 5000001, BioRad, Hercules, CA, USA). Samples were stored at $-20^{\circ} \mathrm{C}$ in preparation for Western Blot analysis. 


\subsection{Immunoprecipitation}

The immunoprecipitation was performed in order to detect GSH/CBS interaction in EA.hy926 cells, treated during $24 \mathrm{~h}$ with $1 \mathrm{mM}$ GSH and/or 0.3 lanthionine as described in Section 4.1. This experiment was performed using Immunoprecipitation Kit-Dynabeads ${ }^{\mathrm{TM}}$ Protein G (00330770, Thermo Fisher Scientific, Vilnius, Lithuania), according to the manifacturer's protocol. Briefly, $100 \mu \mathrm{g}$ of proteins were incubated with Dynabeads crosslinked with the relevant antibody (7 $\mu$ g of anti-GSH, ab19534, Abcam, Cambridge, MA, USA) followed by denaturing elution. Immunoprecipitated samples were loaded onto the gel and analyzed by Western blotting.

\subsection{Western Blotting Analysis}

Proteins were electrophoretically separated on precast gels 8-16\% (456-1104, mini-PROTEANS ${ }^{\circledR}$ TGX ${ }^{\mathrm{TM}}$ Gels, Bio-Rad, Hercules, CA, USA) and transferred onto $0.2 \mu \mathrm{m}$ nitrocellulose membrane (1704158, Trans-Blot ${ }^{\circledR}$ Turbo $^{\mathrm{TM}}$, Bio-Rad, Hercules, CA, USA). Protein detection was performed using the following primary antibodies: anti-CBS (ab140600, Abcam, Cambridge, MA, USA), anti-CSE (ab136604, Abcam, Cambridge, MA, USA), anti-VEGFA (E-AB-11647, Elabscience, Houston, TX, USA). Anti-Actin (E-AB-20031, Elabscience, Houston, TX, USA) and anti-Tubulin (2125S, Cell Signalling, Leiden, WZ, The Netherlands) were employed as loading controls as appropriate. Secondary antibodies anti-rabbit (NC27606, Immunoreagents Inc., Raleigh, NC, USA) and anti-mouse (Immunoreagents Inc., Raleigh, NC, USA) conjugated with horseradish peroxidase were utilized. Detection of the immunocomplexes was obtained by chemiluminescence, utilizing Immobilon Western Chemiluminescent HRP Substrate (WBKLS0500, Millipore Corporation, Billerica, MA, USA) and transilluminator (ChemiDoc ${ }^{\mathrm{TM}}$, Bio-Rad, Hercules, CA, USA). Signal intensity was quantified with ImageJ software.

\subsection{RNA Extraction}

mRNA and miRNA were extracted from cells using mirVana ${ }^{\mathrm{TM}}$ PARISTM ${ }^{\mathrm{TM}}$ (AM1556, ThermoFisher Scientific, Milan, Italy) according to the supplier's protocol. RNA concentration was measured by means of NanoDrop UV/Vis micro-spectrophotometry (ND-1000; NanoDrop Technologies, Wilmington, DE, USA). Samples were stored at $-80^{\circ} \mathrm{C}$.

\subsection{Reverse Transcription, $P C R$ and $q P C R$}

cDNA was synthesized from $1 \mu \mathrm{g}$ of total RNA. For reverse transcription, the QuantiTect ${ }^{\circledR}$ reverse transcription kit and gDNA wipeout (205313, Qiagen, Hilden, Germany) were used according to the supplier's protocol. Reactions were performed in Veriti ${ }^{\circledR}$ 96-Well Thermal Cycler (Applied Biosystems, Foster City, CA, USA). cDNA concentration was measured by means of NanoDrop UV/Vis micro-spectrophotometry. cDNA samples were stored at $-20^{\circ} \mathrm{C}$.

qPCR experiments were performed using $200 \mathrm{ng}$ cDNA, Power SYBR ${ }^{\mathrm{TM}}$ Green PCR Master Mix (4367659, ThermoFisher Scientific, Milan, Italy) and ViiaTM7 Thermal Cycler (Applied Biosystems, Foster City, CA, USA). For total VEGFA amplification, primers were used as according to Medford et al. [34]; VEGFA isoforms -121, -145, -165, -189 were amplified using primer oligonucleotide sequences as described by Wang et al. [33]; VEGFA-183 isoform was amplified using the following primers: forward 5' - GCA AGA AAT CCC GTC CCT GTG G -3' and reverse 5' - TCA CCG CCT CGG CTT GTC ACA T -3'; Amplification conditions were the following: $95^{\circ} \mathrm{C}$ for $15 \mathrm{~min}$, followed by 40 cycles of $94{ }^{\circ} \mathrm{C}$ for $15 \mathrm{~s}$, annealing step was carried out at $61^{\circ} \mathrm{C}$ for $30 \mathrm{~s}$ and $72{ }^{\circ} \mathrm{C}$ for $30 \mathrm{~s}$. To determine the relative quantities of the genes of interest, transcripts present in the various experimental conditions were compared with control. 18S or GAPDH (ThermoFisher Scientific, Milan, Italy), as appropriate, were used as housekeeping genes for all real-time PCR experiments, to normalize the results of the detected transcript levels. Data were handled by Real-Time PCR System ViiaTM7 software. $\Delta \Delta C t$ calculations were also manually verified ("Users bulletin”, ABI PRISM 7700 Sequence Detection System 1997). 


\subsection{0. miRNA Profiling}

miRNA expression was determined using samples obtained from untreated control EA.hy926 cells and cells exposed with $0.3 \mu \mathrm{M}$ lanthionine during 12-48 h. miRNA were retro-transcribed with RT-TaqMan ${ }^{\circledR}$ MicroRNA Assays: miR-200c (RT/TM 002300), miR-423 (RT/TM 002340) (Applied Biosystems, Pleasanton, CA, USA) on Veriti ${ }^{\circledR}$ 96-Well Thermal Cycler, under the following conditions: $16{ }^{\circ} \mathrm{C}$ for $30 \mathrm{~min}, 42{ }^{\circ} \mathrm{C}$ for $30 \mathrm{~min}, 8{ }^{\circ} \mathrm{C}$ for $5 \mathrm{~min}$. Subsequently, cDNA were amplified using corresponding TaqMan ${ }^{\circledR}$ MicroRNA Assays (4366596, Applied Biosystems, Vilnius, Lithuania) on a ViiaTM7 Thermalcycler under the following conditions: $50{ }^{\circ} \mathrm{C}$ for $2 \mathrm{~min}, 95{ }^{\circ} \mathrm{C}$ for $10 \mathrm{~min}$ and $95^{\circ} \mathrm{C}$ for $15 \mathrm{~s}, 60^{\circ} \mathrm{C}$ for $1 \mathrm{~min}$ followed by 40 cycles. Relative quantification was performed using the $\Delta \Delta \mathrm{Ct}$ method using U6 snRNA (RT/TM 0019732, Applied Biosystems, Pleasanton, CA, USA) as a housekeeping gene product. Differential levels of each miRNA expressed were evaluated by the ViiaTM7 software.

\subsection{Bioinformatics Analysis}

The information about pathways involving gene targets for miRNA-200c and miRNA-423 was obtained using the miRSystem software (ver. 20160513-miRNAsystem.cgm.ntu.edu.tw). In order to draw inferences on the potential functional interactions between miRNA and their gene targets, pathways identified were listed according to the KEGG (Kyoto Encyclopedia of Genes and Genomes) pathway map. Relevant nomenclature consists of a molecular network in terms of the KEGG Orthology (KO) groups. miRNA genes targets analysis includes genes selected according to the relevance to processes involved in kidney disease.

\subsection{Statistical Analysis}

Unpaired, two tailed, Student's t-test was utilized to compare means, as appropriate (means were considered significantly different as $p<0.05$ ). Data are expressed as the means \pm standard deviation (SD), except where otherwise specified. Results were analyzed using the statistics software GraphPad Prism Version 5.0 (GraphPad Software, San Diego, CA, USA).

\section{Conclusions}

Lanthionine reduced the $\mathrm{H}_{2} \mathrm{~S}$ release from cell cultures as well as sulfane sulfur, indicating that this amino acid may contribute to the reduction of $\mathrm{H}_{2} \mathrm{~S}$ in uremia. This effect may be at least partly mediated by both CBS downregulation and a reduction of its glutathionylation, which is a known enzyme activating post-biosynthetic modification. These effects are susceptible to partial recovery upon co-incubation with GSH, thus underscoring the relevance to uremia, a condition characterized by oxidative stress and, hence, inflammation. Lanthionine exerted a calcium ionophore role in our system, which was accompanied by an acute inhibitory effects towards the expression of VEGFA. This is likely mediated by an upregulation of miR-200c, which, in fact, is increased in our model upon lanthionine treatment. It has been described that miR-200c stimulates $\mathrm{H}_{2} \mathrm{~S}$ production and exerts an anti-oncogene role. Lanthionine-induced alterations in cell cultures, which span over various aspects including sulfur amino acid metabolism and calcium homeostasis, further support the uremic toxin role of this amino acid.

Supplementary Materials: Supplementary materials can be found at http://www.mdpi.com/1422-0067/20/9/2269/ s1.

Author Contributions: Conceptualization, A.F.P. and D.I.; data curation, C.V., E.A. and P.L.; formal analysis, C.V., E.A., L.M., P.L., M.Z., F.T., G.C.; investigation, E.A. and C.V.; methodology, C.V., E.A. and P.L.; project administration, A.F.P.; resources, A.F.P.; software, C.V., E.A., L.M. and R.C.; supervision, A.F.P. and D.I.; validation, C.V., E.A. and R.C.; visualization, C.V. and E.A.; writing—original draft, A.F.P., D.I., E.A. and C.V.; writing一review \& editing, A.F.P. and D.I. 
Funding: Post-doctoral fellowship of Evgeniya Anishchenko was supported by a grant from Gnosis S.p.A.; Carmela Vigoritos' PhD fellowship was supported by University of Campania "Luigi Vanvitelli". Additional fundings were received from EUTox.

Acknowledgments: The authors are very grateful to Salvatore D'Aniello (Stazione Zoologica Anton Dohrn Napoli, Italy, Department of Biology and Evolution of Marine Organisms) for his useful suggestions during manuscript preparation.

Conflicts of Interest: The authors declare no conflict of interest, except for A.F.P., who received research funding from Gnosis S.p.A. and EUTox. The funders had no role in the design of the study; in the collection, analyses, or interpretation of data; in the writing of the manuscript, or in the decision to publish the results.

\section{Abbreviations}

$\begin{array}{ll}\text { AdoMet } & \text { S-adenosyl- } L \text {-methionine } \\ \mathrm{B}_{6} & \text { Pyridoxalphosphate } \\ \mathrm{Ca}^{2+} & \text { Calcium } \\ \mathrm{CBS} & \text { Cystathionine- } \beta \text {-synthase } \\ \mathrm{CSE} & \text { Cystathionine- } \gamma \text {-lyase } \\ \text { CTRL } & \text { Control } \\ \text { Cys } & \text { Cysteine } \\ \text { GSH } & \text { Glutathione } \\ \mathrm{H}_{2} \mathrm{~S} & \text { Hydrogen sulfide } \\ \text { Lan } & \text { Lanthionine } \\ \text { LAST } & \text { Lead Acetate Strip Test } \\ \text { qPCR } & \text { quantitative Polimerase Chain Reaction } \\ \text { SSP4 } & \text { Sulfane Sulfur Probe } 4 \\ \text { VEGF } & \text { Vascular Endothelial Growth Factor }\end{array}$

\section{References}

1. Kimura, H. Hydrogen sulfide and polysulfides as biological mediators. Molecules 2014, 19, 16146-16157. [CrossRef] [PubMed]

2. Kimura, H. Hydrogen sulfide and polysulfides as signaling molecules. Nitric Oxide 2015, 47, S6. [CrossRef]

3. Chiku, T.; Padovani, D.; Zhu, W.; Singh, S.; Vitvitsky, V.; Banerjee, R. H2S Biogenesis by Human Cystathionine $\gamma$-Lyase Leads to the Novel Sulfur Metabolites Lanthionine and Homolanthionine and Is Responsive to the Grade of Hyperhomocysteinemia. J. Biol. Chem. 2009, 284, 11601-11612. [CrossRef] [PubMed]

4. Majtan, T.; Krijt, J.; Sokolová, J.; Křřžková, M.; Ralat, M.A.; Kent, J.; Gregory, J.F., III; Kožich, V.; Kraus, J.P. Biogenesis of Hydrogen Sulfide and Thioethers by Cystathionine Beta-Synthase. Antioxid. Redox Signal. 2018, 28, 311-323. [CrossRef]

5. Kabil, O.; Banerjee, R. Enzymology of H2S biogenesis, decay and signaling. Antioxid. Redox Signal. 2014, 20, 770-782. [CrossRef] [PubMed]

6. Perna, A.F.; Di Nunzio, A.; Amoresano, A.; Pane, F.; Fontanarosa, C.; Pucci, P.; Vigorito, C.; Cirillo, G.; Zacchia, M.; Trepiccione, F; et al. Divergent behavior of hydrogen sulfide pools and of the sulfur metabolite lanthionine, a novel uremic toxin, in dialysis patients. Biochimie 2016, 126, 97-107. [CrossRef]

7. Perna, A.F.; Anishchenko, E.; Vigorito, C.; Zacchia, M.; Trepiccione, F.; D’Aniello, S.; Ingrosso, D. Zebrafish, a Novel Model System to Study Uremic Toxins: The Case for the Sulfur Amino Acid Lanthionine. Int. J. Mol. Sci. 2018, 19, 1323. [CrossRef] [PubMed]

8. Bibli, S.I.; Luck, B.; Zukunft, S.; Wittig, J.; Chen, W.; Xian, M.; Papapetropoulos, A.; Hu, J.; Fleming, I. A selective and sensitive method for quantification of endogenous polysulfide production in biological samples. Redox Biol. 2018, 18, 295-304. [CrossRef] [PubMed]

9. Mustafa, A.K.; Gadalla, M.M.; Sen, N.; Kim, S.; Mu, W.; Gazi, S.K.; Barrow, R.K.; Yang, G.; Wang, R.; Snyder, S.H. H2S signals through protein S-sulfhydration. Sci. Signal. 2009, 2, ra72. [CrossRef] [PubMed]

10. Vitvitsky, V.; Yadav, P.K.; An, S.; Seravalli, J.; Cho, U.S.; Banerjee, R. Structural and Mechanistic Insights into Hemoglobin-catalyzed Hydrogen Sulfide Oxidation and the Fate of Polysulfide Products. J. Biol. Chem. 2017, 292, 5584-5592. [CrossRef] [PubMed] 
11. Anishchenko, E.; Vigorito, C.; Mele, L.; Lombari, P.; Perna, A.; Ingrosso, D. Novel Applications of Lead Acetate and Flow Cytometry Methods for Detection of Sulfur-Containing Molecules. Methods Protoc. 2019, 2, 13. [CrossRef]

12. Ida, T.; Sawa, T.; Ihara, H.; Tsuchiya, Y.; Watanabe, Y.; Kumagai, Y.; Suematsu, M.; Motohashi, H.; Fujii, S.; Matsunaga, T.; et al. Reactive cysteine persulfides and S-polythiolation regulate oxidative stress and redox signaling. Proc. Natl. Acad. Sci. USA 2014, 111, 7606-7611. [CrossRef]

13. Niu, W.N.; Yadav, P.K.; Adamec, J.; Banerjee, R. S-glutathionylation enhances human cystathionine $\beta$-synthase activity under oxidative stress conditions. Antioxid. Redox Signal. 2015, 22, 350-361. [CrossRef]

14. Pavkovic, M.; Robinson-Cohen, C.; Chua, A.S.; Nicoara, O.; Cárdenas-González, M.; Bijol, V.; Ramachandran, K.; Hampson, L.; Pirmohamed, M.; Antoine, D.J.; et al. Detection of Drug-Induced Acute Kidney Injury in Humans Using Urinary KIM-1, miR-21, -200c, and -423. Toxicol. Sci. 2016, 152, 205-213. [CrossRef]

15. Ramachandran, K.; Saikumar, J.; Bijol, V.; Koyner, J.L.; Qian, J.; Betensky, R.A.; Waikar, S.S.; Vaidya, V.S. Human miRNome profiling identifies microRNAs differentially present in the urine after kidney injury. Clin. Chem. 2013, 59, 1742-1752. [CrossRef]

16. Wang, J.; Wang, X.H.; Wang, H.; Chen, L.; Klein, J.D.; Sands, J.M. Urea Transporter B and MicroRNA-200c Differ in Kidney Outer Versus Inner Medulla Following Dehydration. Am. J. Med. Sci. 2016, 352, $296-301$. [CrossRef]

17. Szeto, C.-C. Urine miRNA in nephrotic syndrome. Clin. Chim. Acta 2014, 436, 308-313. [CrossRef]

18. Lv, L.L.; Cao, Y.; Liu, D.; Xu, M.; Liu, H.; Tang, R.N.; Ma, K.L.; Liu, B.C. Isolation and Quantification of MicroRNAs from Urinary Exosomes/Microvesicles for Biomarker Discovery. Int. J. Biol. Sci. 2013, 9, 1021-1031. [CrossRef]

19. Sataranatarajan, K.; Feliers, D.; Mariappan, M.M.; Lee, H.J.; Lee, M.J.; Day, R.T.; Yalamanchili, H.B.; Choudhury, G.G.; Barnes, J.L.; Van Remmen, H.; et al. Molecular events in matrix protein metabolism in the aging kidney. Aging Cell 2012, 11, 1065-1073. [CrossRef]

20. Yuan, X.P.; Liu, L.S.; Chen, C.B.; Zhou, J.; Zheng, Y.T.; Wang, X.P.; Han, M.; Wang, C.X. MicroRNA-423-5p facilitates hypoxia/reoxygenation-induced apoptosis in renal proximal tubular epithelial cells by targeting GSTM1 via endoplasmic reticulum stress. Oncotarget 2017, 8, 82064-82077. [CrossRef]

21. Koo, T.; Cho, B.J.; Kim, D.H.; Park, J.M.; Choi, E.J.; Kim, H.H.; Lee, D.J.; Kim, I.A. MicroRNA-200c increases radiosensitivity of human cancer cells with activated EGFR-associated signaling. Oncotarget 2017, 8, 65457-65468. [CrossRef]

22. Zygalaki, E.; Kaklamanis, L.; Nikolaou, N.I.; Kyrzopoulos, S.; Houri, M.; Kyriakides, Z.; Lianidou, E.S.; Kremastinos, D.T. Expression profile of total VEGF, VEGF splice variants and VEGF receptors in the myocardium and arterial vasculature of diabetic and non-diabetic patients with coronary artery disease. Clin. Biochem. 2008, 41, 82-87. [CrossRef]

23. Potenza, D.M.; Guerra, G.; Avanzato, D.; Poletto, V.; Pareek, S.; Guido, D.; Gallanti, A.; Rosti, V.; Munaron, L.; Tanzi, F.; et al. Hydrogen sulphide triggers VEGF-induced intracellular Ca2 signals in human endothelial cells but not in their immature progenitors. Cell Calcium 2014, 56, 225-234. [CrossRef]

24. Perna, A.F.; Glorieux, G.; Zacchia, M.; Trepiccione, F.; Capolongo, G.; Vigorito, C.; Anishchenko, E.; Ingrosso, D. The role of the intestinal microbiota in uremic solute accumulation: a focus on sulfur compounds. J. Nephrol. 2019. [CrossRef]

25. Perna, A.F.; Ingrosso, D.; Satta, E.; Lombardi, C.; Acanfora, F.; De Santo, N.G. Homocysteine metabolism in renal failure. Curr. Opin. Clin. Nutr. Metab. Care 2004, 7, 53-57. [CrossRef]

26. Perna, A.F. Plasma Protein Aspartyl Damage Is Increased in Hemodialysis Patients: Studies on Causes and Consequences. J. Am. Soc. Nephrol. 2004, 15, 2747-2754. [CrossRef]

27. Ferrara, N. Vascular Endothelial Growth Factor: Basic Science and Clinical Progress. Endocr. Rev. 2004, 25, 581-611. [CrossRef]

28. Shih, S.C.; Ju, M.; Liu, N.; Mo, J.R.; Ney, J.J.; Smith, L.E.H. Transforming growth factor beta1 induction of vascular endothelial growth factor receptor 1: mechanism of pericyte-induced vascular survival in vivo. Proc. Natl. Acad. Sci. USA 2003, 100, 15859-15864. [CrossRef]

29. Frangié, C.; Lefaucheur, C.; Medioni, J.; Jacquot, C.; Hill, G.S.; Nochy, D. Renal thrombotic microangiopathy caused by anti-VEGF-antibody treatment for metastatic renal-cell carcinoma. Lancet Oncol. 2007, 8, 177-178. [CrossRef] 
30. Eremina, V.; Cui, S.; Gerber, H.; Ferrara, N.; Haigh, J.; Nagy, A.; Ema, M.; Rossant, J.; Jothy, S.; Miner, J.H.; et al. Vascular endothelial growth factor a signaling in the podocyte-endothelial compartment is required for mesangial cell migration and survival. J. Am. Soc. Nephrol. 2006, 17, 724-735. [CrossRef]

31. Jingjing, L.; Srinivasan, B.; Roque, R.S. Ectodomain shedding of VEGF183, a novel isoform of vascular endothelial growth factor, promotes its mitogenic activity in vitro. Angiogenesis 2001, 4, 103-112. [CrossRef]

32. Houck, K.A.; Ferrara, N.; Winer, J.; Cachianes, G.; Li, B.; Leung, D.W. The vascular endothelial growth factor family: identification of a fourth molecular species and characterization of alternative splicing of RNA. Mol. Endocrinol. 1991, 5, 1806-1814. [CrossRef]

33. Wang, X.-F.; Cui, J.Z.; Prasad, S.S.; Matsubara, J.A. Altered gene expression of angiogenic factors induced by calcium-mediated dissociation of retinal pigment epithelial cells. Invest. Ophthalmol. Vis. Sci. 2005, 46, 1508-1515. [CrossRef] [PubMed]

34. Medford, A.R.L.; Douglas, S.K.; Godinho, S.I.H.; Uppington, K.M.; Armstrong, L.; Gillespie, K.M.; van Zyl, B.; Tetley, T.D.; Ibrahim, N.B.N.; Millar, A.B. Vascular Endothelial Growth Factor (VEGF) isoform expression and activity in human and murine lung injury. Respir. Res. 2009, 10, 27. [CrossRef] [PubMed]

35. Azimi-Nezhad, M. Vascular endothelial growth factor from embryonic status to cardiovascular pathology. Rep. Biochem. Mol. Biol. 2014, 2, 59-69.

36. Bergantino, F.; Guariniello, S.; Raucci, R.; Colonna, G.; De Luca, A.; Normanno, N.; Costantini, S. Structure-fluctuation-function relationships of seven pro-angiogenic isoforms of VEGFA, important mediators of tumorigenesis. Biochim. Biophys. Acta-Proteins Proteom. 2015, 1854, 410-425. [CrossRef] [PubMed]

37. Tessler, S.; Rockwell, P.; Hicklin, D.; Cohen, T.; Levi, B.Z.; Witte, L.; Lemischka, I.R.; Neufeld, G. Heparin modulates the interaction of VEGF165 with soluble and cell associated flk-1 receptors. J. Biol. Chem. 1994, 269, 12456-12461. [PubMed]

38. McCullough, P.A.; Agarwal, M.; Agrawal, V. Review article: Risks of coronary artery calcification in chronic kidney disease: do the same rules apply? Nephrology 2009, 14, 428-436. [CrossRef]

39. Coletta, C.; Papapetropoulos, A.; Erdelyi, K.; Olah, G.; Modis, K.; Panopoulos, P.; Asimakopoulou, A.; Gero, D.; Szabo, C. P23 The angiogenic and vasorelaxant effect of $\mathrm{H} 2 \mathrm{~S}$ require the endogenous production of $\mathrm{NO}$, while the angiogenic and vasorelaxant effect of $\mathrm{NO}$ require the endogenous production of $\mathrm{H} 2 \mathrm{~S}$. Nitric Oxide 2012, 27, S22-S23. [CrossRef]

40. Vicente, J.B.; Malagrinò, F.; Arese, M.; Forte, E.; Sarti, P.; Giuffrè, A. Bioenergetic relevance of hydrogen sulfide and the interplay between gasotransmitters at human cystathionine $\beta$-synthase. Biochim. Biophys. Acta 2016, 1857, 1127-1138. [CrossRef]

41. Vicente, J.B.; Colaço, H.G.; Malagrinò, F.; Arese, M.; Forte, E.; Sarti, P.; Leandro, P.; Giuffrè, A. S-adenosyl-L-methionine and the Cross-talk between the Bioenergetically Relevant Gasotransmitters H $2 \mathrm{~S}$, $\mathrm{NO}$ and $\mathrm{CO}$ at Human Cystathionine $\beta$-synthase. Biochim. Biophys. Acta-Bioenergetics 2016, 1857, e81-e82. [CrossRef]

(C) 2019 by the authors. Licensee MDPI, Basel, Switzerland. This article is an open access article distributed under the terms and conditions of the Creative Commons Attribution (CC BY) license (http://creativecommons.org/licenses/by/4.0/). 